\title{
Patient report on information given, consultation time and safety in primary care
}

\author{
José Joaquín Mira, ${ }^{1,2}$ Cristina Nebot, ${ }^{3}$ Susana Lorenzo, ${ }^{4}$ Virtudes Pérez-Jover ${ }^{2}$
}

${ }^{1}$ Sexual and Reproductive Health, Centro Salud

Hospital-Plá, Alicante, Spain

${ }^{2}$ Health Psychology Department, Universidad Miguel Hernández, Elche, Spain

${ }^{3}$ Patient Affairs Department, Consellería de Sanitat, Valencia, Spain

${ }^{4}$ Quality Department, Hospital Universitario Fundación Alcorcón, Alcorcón, Madrid, Spain

\section{Correspondence to}

Professor José Joaquín Mira, Universidad Miguel Hernández de Elche, Avda. Universidad s/n, Elche 03202, Alicante, Spain; jose.mira@umh.es

Preliminary results of this study were presented at the 24th ISQua International Conference. Boston (USA), in October 2007.

Accepted 7 January 2010 Published Online First 27 May 2010

\begin{abstract}
Objective To analyse the frequency of adverse events to treatment reported by patients in relation to consultation time, attention from their usual doctor and information provided by their doctor about treatment.

Design Descriptive study. Patients were invited to respond to a telephone survey.

Setting 21 Primary Care health centres in Spain. Participants 15282 patients attended by GPs or paediatricians (error of $1 \%$ for $p=q=0.50, \alpha 95 \%$ ) were selected at random from the total consultations recorded in 1 month. For sampling, quotas were assigned for type of attention, age and sex. In the case of children (under 14 years), the survey was answered by their parents.
\end{abstract}

Main outcome measures Patients' report on frequency of unexpected or adverse reaction to a treatment; whether informed or not about possible complications of the treatment and precautions to take; consultation time; and whether or not patient is usually seen by the same doctor.

Results 1557 (17.6\%, Cl 95\% 16.8 to $18.4 \%)$ of the adults and $867(13.7 \%, 95 \% \mathrm{Cl} 12.8$ to $14.5 \%)$ of the children reported adverse or unexpected reactions to the treatment according to patients' reports. Consultation time (OR $0.5,95 \% \mathrm{Cl} 0.4$ to 0.5 ), doctor rotation at the health centre (OR 2.04,95\% Cl 1.85 to 2.25 ) and information on treatment precautions (OR $0.47,95 \% \mathrm{Cl}$ 0.43 to 0.53 ) determine the higher risk of adverse reactions to treatment.

Conclusions Planning at health centres should involve the monitoring of mean consultation time and doctor rotation as indirect indicators of safety. Furthermore, protocols related to the information provided to patients should be reviewed.

\section{INTRODUCTION}

In countries such as Australia, Ireland, Portugal, Spain or the UK, the public health system starts at the primary care level. At our health centres, GPs attend adults and paediatricians attend children.

Avoiding adverse events (AE) has become a commitment for health services across the world. Although the majority of studies on clinical safety have focused on the hospital context, it is becoming more and more relevant to discern what happens in the primary care level (PC) ${ }^{1-3}$ Moreover, any approach to increasing clinical safety in PC has a multiplying effect, given the large numbers of patients attended annually at healthcare centres. It should also be kept in mind that at this level of care, patients tend to be older and with multimorbidity, and therefore at greater risk of suffering AEs. ${ }^{4}$

Researchers have highlighted the difficulties of carrying out studies on the incidence of AEs in PC. ${ }^{5}$ AEs are usually identified from voluntary state- ments made by physicians or through medical records screening studies. In the UK, researchers have identified 7.6 clinical errors per 100 consultations in PC. ${ }^{6}$ In Spain, it has been estimated that each, year seven out of every 100 patients will suffer an $\mathrm{AE}$ at this care level ${ }^{7}$ and that each GP will be involved in 11 AEs per year. ${ }^{8}$ In these studies, a majority of AEs identified are related to the administration of drugs, ${ }^{1}{ }^{9}$ but a quarter derive from problems of doctor-patient communication, ${ }^{7}$ and this has been interpreted as a symptom of organisational problems in Health Services. ${ }^{10}$

The patient has also been considered as an alternative informant for determining the frequency of clinical errors, ${ }^{11-13}$ but a majority of studies assessing patients' views make their enquiries only after hospital discharge. ${ }^{14-16}$ In some of these studies, researchers asked patients directly about clinical errors, ${ }^{16}$ while others showed them a list of AEs to identify a number of them, ${ }^{17}$ or confronted patients with examples to elicit a response. ${ }^{12} 18$ Studies of the clinical errors reported by PC patients suggest that they are more likely to be related to breakdowns in the clinical-patient relationship than to technical errors. $^{2}$

Despite the fact that both screening studies and patient interviews indicate that deficient doctor-patient communication is one of the causes of AEs, few studies have analysed this issue in detail. So far, research has systematically examined the effect of doctors' working style on patient satisfaction and treatment adherence, ${ }^{19-25}$ but little is known about whether the information provided by GPs and the possibility of interaction with them contributes to any extent to patient safety.

It can be expected that lack of time ${ }^{26}$ and/or deficient information provided by the doctor about treatment precautions ${ }^{27}$ will have a negative effect on clinical safety; in turn, we would expect that if the doctor has enough available consultation time and takes advantage of it, informing patients in a way that lets them take a more active role, the risk of AEs might be reduced. ${ }^{15} 28$ This study aimed to analyse, from the patients' point of view, the relationships between, on the one hand, certain organisational aspects (consultation time, whether or not the patient is normally seen by the same doctor), information provided about possible complications and precautions to be taken, and on the other hand, the frequency of adverse reactions to treatment or unexpected effects.

\section{METHODS}

Descriptive study in which 19208 patients attended by GPs and paediatricians at Spanish health centres were invited to respond to 
Table 1 Percentage of patients considering themselves to have been correctly informed of the precautions to take in the course of treatment, mean duration of the consultation and whether or not the patient is normally attended by the same doctor

\begin{tabular}{|c|c|c|c|c|}
\hline \multicolumn{3}{|l|}{$\mathbf{G P}$} & \multicolumn{2}{|l|}{ Paediatrician } \\
\hline & $\begin{array}{l}\text { Patient informed of } \\
\text { precautions to take, } \\
\mathbf{N}(\%)^{*}\end{array}$ & $\begin{array}{l}\text { Not informed, } \\
\text { N }(\%)\end{array}$ & $\begin{array}{l}\text { Patient informed of } \\
\text { precautions to take, } \\
\mathrm{N}(\%)^{*}\end{array}$ & $\begin{array}{l}\text { Not informed, } \\
\text { N (\%) }\end{array}$ \\
\hline Less than $10 \mathrm{~min}$ & $748(30.5)$ & $1705(69.5)$ & $297(22.8)$ & $1003(77.2)$ \\
\hline $11-20 \mathrm{mn}$ & $827(16.7)$ & 4122 (83.3) & $378(10.5)$ & 3217 (89.5) \\
\hline More than $20 \mathrm{~min}$ & $183(11.8)$ & 1368 (88.2) & $90(6.3)$ & 1344 (93.7) \\
\hline Same doctor normally seen & $1196(16.7)$ & 5959 (83.3) & $499(9.8)$ & $4599(90.2)$ \\
\hline Frequent change of doctor & $562(31.3)$ & $1236(68.7)$ & $266(21.6)$ & $965(78.4)$ \\
\hline
\end{tabular}

a telephonic survey (sample size was calculated for each group for a maximum error of $1 \%, p=q=0.50, \alpha 95 \%$ ).

Patients were asked about their experience with GPs or paediatricians on seeking treatment for an acute or chronic problem. The survey included a direct question for assessing the extent to which the treatment prescribed by the doctor had not gone completely well ('Did you need to return to the doctor because of an unexpected or undesired reaction to the treatment?'). Based on previous results ${ }^{13} 17182930$ which revealed the problems associated with using patients as informants, it was decided to discard asking respondents directly whether they had suffered an AE, choosing instead this indirect indicator to identify possible difficulties in the course of the treatment. The survey also included a series of questions: (1) to rate the information provided by the doctor (whether they had informed the patient of possible complications of the treatment prescribed and of the precautions to be taken; (2) to analyse whether the doctor attending the respondent at the health centre (the duty doctor) frequently changed; and (3) to assess the length of consultation time. In this last case, two measures were taken: time in minutes and patients' perception of whether they had had sufficient time to talk to the doctor. All these questions had been used in previous studies on perceived clinical safety, which checked their facial validity, understanding and necessary response time. ${ }^{15}$

Patients were selected at random from the total consultations recorded for the previous month at all the participating health centres. In the sampling, quotas were assigned for type of care, age and sex, in accordance with the routine care activity at health centres. In the case of children, the survey was answered by their parents (or guardians) who attended the consultation room with them. The field study concluded when the quota for each group of respondents was reached according to the fixed sampling size.
Data analysis was carried out with $\chi^{2}$ for categorical variables, applying the Yates correction in $2 \times 2$ tables. In successive analyses, we considered as adjustment variables age, sex and whether or not the problem was chronic. We used a logistic regression model, considering as (dichotomised) dependent variable: whether the patient had experienced unexpected reaction to the treatment which had meant they had to return to the doctor, and as independent variables: responses to the questions on consultation time, on doctor rotation at the health centre and on information provided about treatment precautions. In line with convention, differences were considered to be statistically significant when $\mathrm{p}<0.05$ for a confidence level of $95 \%$.

\section{RESULTS}

A total of 15282 patients responded to the survey (response rate: $79.6 \%$ ). Of these, 8953 were seen by GPs and 6329 by paediatricians. A total of $38 \%$ of the adult patients were aged over 60 , and $61.6 \%$ were women. Among the adults, $81.8 \%$ had a chronic health problem. In the case of children, $86.4 \%$ of the adults who responded to the survey on their behalf were female, and $84.7 \%$ were aged under 40 .

\section{Consultation time, change of doctor and information provided in relation to safety}

The length of the consultation was less than $10 \mathrm{~min}$ in 2453 cases $(27.4 \%)$ of adult patient cases and 1300 (20.5\%) of paediatric cases.

In total, 1798 (20.1\%) of the adult patients and 1231 (19.5\%) of the paediatric patients reported that the duty doctor at their health centre frequently changed. There was a relationship between the reported frequency with which the doctor changed and usual length of consultations; moreover, an increase in the frequency of doctor exchange made it more likely that

Table 2 Patient reports needing a second visit to the doctor due to complications in the course of the treatment

\begin{tabular}{|c|c|c|c|c|}
\hline & OR & $95 \% \mathrm{Cl}$ & & p Value \\
\hline \multicolumn{5}{|l|}{ Duration of consultation } \\
\hline$<10 \min$ & 1.00 & & & 0.01 \\
\hline $11-20 \mathrm{~min}$ & 1.21 & 1.05 & 1.39 & 0.01 \\
\hline$>20 \min$ & 1.07 & 0.94 & 1.21 & 0.30 \\
\hline Frequent change of doctor & 2.04 & 1.85 & 2.25 & 0.001 \\
\hline $\begin{array}{l}\text { Feeling of having sufficient time to talk to } \\
\text { the doctor }\end{array}$ & 0.47 & 0.42 & 0.54 & 0.001 \\
\hline $\begin{array}{l}\text { Doctor informed patient about possible } \\
\text { complications and precautions to be taken }\end{array}$ & 0.47 & 0.43 & 0.53 & 0.001 \\
\hline
\end{tabular}

Simple total $\mathrm{N}=15282$. OR for patient report of complications in the course of the treatment, necessitating a second visit to the doctor. The $95 \% \mathrm{Cl}$ is for the $\mathrm{OR}$ value. 
Table 3 Percentage of patients requesting a second consultation because of complications or unexpected effects in the course of the prescribed treatment, according to whether or not they consider having been correctly informed of the precautions to take

\begin{tabular}{|c|c|c|c|c|}
\hline & \multicolumn{2}{|l|}{ GP } & \multicolumn{2}{|l|}{ Paediatrician } \\
\hline & $\begin{array}{l}\text { Patient informed of } \\
\text { precautions to take* } \\
\text { N (\%) }\end{array}$ & $\begin{array}{l}\text { Not informed } \\
\text { N (\%) }\end{array}$ & $\begin{array}{l}\text { Patient informed of } \\
\text { precautions to take* } \\
\mathrm{N}(\%)\end{array}$ & $\begin{array}{l}\text { Not informed } \\
\text { N (\%) }\end{array}$ \\
\hline $\begin{array}{l}\text { Patient reported complications with } \\
\text { treatment }\end{array}$ & $542(34.4)$ & $1035(65.6)$ & $231(26.6)$ & $636(73.4)$ \\
\hline
\end{tabular}

*Informed about potential complications and the precautions to take in relation to the treatment prescribed.

All $\mathrm{p}<0.001$.

consultation time would be generally short (GP $p<0.001$; paediatrics $\mathrm{p}<0.001)$.

In $1758(19.6 \%)$ cases, GPs had not informed their patients of the potential complications of the treatment. Paediatricians omitted to provide such information in $765(12.1 \%)$ cases.

The frequency with which patients reported having been informed about possible complications and about the precautions to take with the treatment decreased when the consultation lasted less than $10 \mathrm{~min}$ (GP $p<0.001$; paediatrics $\mathrm{p}<0.0001$ ), and also when the patient was not normally seen by the same doctor (GP $\mathrm{p}<0.001$; paediatrics $\mathrm{p}<0.0001)$ (table 1).

Information on safety provided, duration of consultation, change of doctor and complications in the course of the treatment

It was found that $1577(17.6 \%$, CI $95 \% 16.8$ to $18.4 \%)$ of the adults and $867(13.7 \%$, CI $95 \% 12.8$ to $14.5 \%)$ of the minors had requested a second consultation due to some adverse or unexpected reaction to the treatment prescribed by their doctor. Of the adult patients, $33.6 \%$ were aged over $60(p=0.04)$.

Not being informed about treatment precautions, shorter duration of consultation and frequent change of doctor had substantial effects on the number of patients who reported unexpected reactions to their treatment (table 2).

Both adult patients $(\mathrm{p}<0.0001)$ and paediatric patients $(p<0.0001)$ who reported not having been informed about precautions and/or potential complications in relation to their treatment are those who report more often having had to return to the health centre because of some problem with the treatment (table 3). No effects were found for the variables age, sex or whether or not the problem was chronic.

When the consultation with the GP or paediatrician lasted less than 10 min (table 4), an increase was found in the number of patients who reported more often requiring a second consulta- tion due to unexpected reactions to their treatment (GP $p<0.001$; paediatrics $p<0.0001)$. The same trend was found when the patient was not seen by their usual doctor (GP $\mathrm{p}<0.01$; paediatrics $\mathrm{p}<0.001)$. Neither sex, age nor nature of the problem (acute or chronic) modified the trend of the results.

\section{DISCUSSION}

Although the study design does not allow us to infer causal relations or to determine the prevalence of AEs in PC, the results highlight the fact that factors related to healthcare organisation and doctor-patient communication are associated with higher risk of incidents and with a drain on resources, confirming previous results. ${ }^{31}$

In $\mathrm{PC}$, the figures for $\mathrm{AE}$ are difficult to determine. ${ }^{32}$ However, in the Spanish setting, ${ }^{7}$ it can be expected that at least $7 \%$ of patients (somewhat less in paediatrics) will suffer an $\mathrm{AE}$ in the course of a year. Although the design of this study does not allow us to draw conclusions about the percentage of patients who experience harm in the course of the treatment, we can assume that among those requesting a second consultation because the treatment had not gone completely well, the percentage of patients who experienced an $\mathrm{AE}$ will tend to be higher. In our case, 18 out of 100 adult patients and a smaller figure for paediatric patients reported that the treatment had not gone completely well, to the extent that it was necessary to return and see the doctor again. The study methodology is totally different from that used in screening studies. In screening studies after the identification phase, each is reviewed to determine if it was a real AE. If we consider only the suspicious cases of $\mathrm{AE}$ (around 14\%), figures would increased. However, it is probable that our figure includes those patients who request a second consultation to change the drug posology and those

Table 4 Percentage of patients requesting a second consultation because of complications or unexpected effects in the course of the prescribed treatment, according to the mean duration of the consultation

\begin{tabular}{|c|c|c|c|c|}
\hline & \multicolumn{2}{|l|}{ GP } & \multicolumn{2}{|l|}{ Paediatrician } \\
\hline & $\begin{array}{l}\text { Patient reported } \\
\text { unexpected effects } \\
\text { N }(\%)\end{array}$ & $\begin{array}{l}\text { Patient did not report } \\
\text { unexpected effects } \\
\text { N (\%) }\end{array}$ & $\begin{array}{l}\text { Patient reported } \\
\text { unexpected effects } \\
\text { N }(\%)\end{array}$ & $\begin{array}{l}\text { Patient did not repor } \\
\text { unexpected effects } \\
N(\%)\end{array}$ \\
\hline$<10 \min ^{*}$ & $529(21.6)$ & $1924(78.4)$ & $249(19.2)$ & $1051(80.8)$ \\
\hline $11-20 \mathrm{~min}$ & $812(16.4)$ & $4137(83.6)$ & $460(12.8)$ & 3135 (87.2) \\
\hline$>20$ min & $236(15.2)$ & $1315(84.8)$ & $158(11.0)$ & $1276(89.0)$ \\
\hline Insufficient consultation time $†$ & $355(35.4)$ & $647(64.6)$ & $168(35.7)$ & $303(64.3)$ \\
\hline Sufficient time & $1222(15.4)$ & $6729(84.6)$ & $699(11.9)$ & $5159(88.1)$ \\
\hline Same doctor usually seen & $1056(14.8)$ & 6099 (85.2) & $557(10.9)$ & 4541 (89.1) \\
\hline Doctor frequently changed & $521(29.0)$ & $1277(71.0)$ & $310(25.2)$ & $921(74.8)$ \\
\hline Total patients & $1577(17.6)$ & $7376(82.4)$ & $867(13.7)$ & $5462(86.3)$ \\
\hline
\end{tabular}

Data as a percentage represent the frequency of patients reporting having needed to return to the health centre because something went wrong with the treatment. All $p<0.001$.

* Mean duration of the consultation.

†Patient perception of whether or not consultation time was sufficient. 
who ask to see their own family physician ( $20 \%$ of the patients refer GP rotation).

Communication with the patient is a key element for the quality of healthcare. ${ }^{33-35}$ In $\mathrm{PC}$, both the duration of the consultation and the GP's working style influence the result of this communication, ${ }^{36}$ which is considered to be one of the main causes of AEs in PC. ${ }^{37}$ It is common for GPs to inform patients of probable diagnosis, aetiology and the treatment and dose appropriate to each case. However, it is not so common for them to inform patients of the precautions to be taken or potential complications in the course of the treatment. ${ }^{38}$ This shortcoming also means that the patient needs further consultations, and in this case, where the patient did not have information on the potential complications or undesired effects of the treatment, there is increased risk (at least) that they will require a second consultation with the doctor about what is understood to be a negative reaction to the treatment.

This study concerns an indirect measure of clinical safety, based on information provided by patients. Although the profile of those who answered the survey corresponds to the profile of the patients who attended in PC, there are a number of limitations. The first is precisely that the study does not directly identify AEs in PC practice. That is the reason why we might find AEs in a number of successive visits required as part of the prescribed treatment. Second, the fact that patients do not consider themselves to have been sufficiently informed does not necessarily imply that the doctor has not explained the risks and precautions: the patient may simply have misunderstood them. Third, the consultation time measures are both based on subjective estimations, and the results might differ if the measures were objective. Fourth, we should bear in mind that Spanish patients visit their health centre more than seven times per year, ${ }^{39}$ so caution should be taken into account when generalising these figures.

Undoubtedly, when a negative reaction to drugs occurs, the primary victim is the patient who suffers the direct consequences. However, we should also take into account a 'second victim': the health professional involved. ${ }^{40}$ The healthcare organisation factors we have studied affect both actors in the care process. Improvements in clinical safety will involve avoiding diagnostic errors and ensuring adequate training of professionals so that they are better equipped to make the right clinical decisions, but the necessary improvements will also mean looking at organisational aspects such as those studied, and which are identified by both direct and indirect sources as risk factors.

Funding Spanish Health Research Fund (Fondo de Investigaciones Sanitarias), reference PI06-90043. c/ Sinesio Delgado, 6 Madrid 28029.

Competing interests None.

Patient consent Obtained from the parents.

Provenance and peer review Not commissioned; externally peer reviewed.

\section{REFERENCES}

1. Makeham MA, Dovey SM, County M, et al. An international taxonomy for errors in general practice: a pilot study. Med J Aust 2002;177:68-72.

2. Kuzel AJ, Woolf SH, Gilchrist VJ, et al. Patient reports of preventable problems and harms in primary health care. Ann Fam Med 2004:2:333-40.

3. Hickner J, Graham DG, Elder NC, et al. Testing process errors and their harms and consequences reported from family medicine practices: a study of the American Academy of Family Physicians National Research Network. Oual Saf Health Care 2008;17:194-200

4. Wilson RM, Runciman WB, Gibberd RW, et al. The quality in Australian health care study. Med J Aust 1995; 163:458-71.

5. Britt H, Miller GC, Steven ID, et al. Collecting data on potentially harmful events: a method for monitoring incidents in general practice. Family Practice 1997; 14:101-6.
6. Rubin G, George A, Chinn DJ, et al. Errors in general practice: development of an error classification and pilot study of a method for detecting errors. Qual Saf Health Care 2003:12:443-7.

7. Aranaz JM, Aibar C, Vitaller J, et al. Estudio APEAS: estudio sobre la seguridad de los pacientes en atención primaria de salud. Madrid: Ministerio de Sanidad y Consumo (España), 2008. http://www.msc.es(acceded 22 Jun 2008).

8. Borrell F, Páez C, Suñol R, et al. Errores clínicos y eventos adversos: percepción de los médicos de atención primaria. Aten Primaria. 2006;38:25-32.

9. Gandhi TK, Weingart SN, Borus J, et al. Adverse drugs events in Ambulatory Care. N Eng J Med 2003;348:1556-64.

10. Wilson T, Sheikh A. Enhancing public safety in primary care. BMJ 2002;321:581-7.

11. Evans SM, Berry JG, Smith BJ, et al. Consumer perceptions of safety in hospitals. BMC Public Health 2006;6:41. (acceded 12 Feb 2009). http://www.biomedcentral. com/1471-2458/6/41/prepub.

12. Blendon RJ, DesRoches $C M$, Brodie $M$, et al. Views of practicing physicians and the public on medical errors. N Engl J Med 2002;347:1933-40.

13. Mira JJ, Aranaz J, Vitaller J, et al. Patients' perception of hospital safety. In: Øvretveit J, Sousa P, eds. Quality and Safety Improvement Research: methods and research practice from the international quality improvement research network (QIRN). Lisbon: Escola Nacional de Saúde Pública and MMC Karolinska Institutet, 2008.

14. Adams RE, Boscarino JA. A community survey of medical errors in New York. Int $J$ Qual Health Care 2004:16:353-62.

15. Mira JJ, Aranaz JM, Vitaller J, et al. Percepción de seguridad clínica tras el alta hospitalaria. Med Clin (Barc) 2008;131(Suppl 3):26-32.

16. Northcott H, Vanderheyden L, Northcott J, et al. Perceptions of preventable medica errors in Alberta, Canada. Int J Qual Health Care 2008;20:115-22.

17. Burroughs TE, Waterman AD, Gallagher TH, et al. Patient concerns about medica errors in emergency departments. Acad Emerg Med 2005:12:57-64.

18. Hobgood C, Peck CR, Gilbert B, et al. Medical errors - what and when: what do patients want to know? Acad Emerg Med 2002;9:1156-61.

19. Di Caccavo A, Ley A, Reid F. What do general practitioners discuss with their patients? exploring the relationship between content of medical consultations and treatment decisions. J Health Psychol 2000:5:87-97.

20. Buller MK, Buller DB. Physicians' communication style and patient satisfaction. $J$ Health Soc Behav 1987;28:375-88.

21. Huygen FJA, Mokkink HGA, Smits AJA, et al. Relationship between the working styles of general practitioners and the health status of their patients. $\mathrm{Br} J \mathrm{Gen}$ Practice 1992; 42:141-4

22. Howie JGR, Porter AMD, Forbes JF. Quality and the use of time in general practice: widening the discussion. BMJ 1989;298:1008-10.

23. Bertakis KD, Roter D, Putnam SM. The relationship of physician medical interview style to patient satisfaction. J Fam Pract 1991;32:175-81.

24. DiMatteo MR, Sherbourne CD, Hays RD, et al. Physicians' characteristics influence patients' adherence to medical treatment: results from the medical outcomes study. Health Psychology 1993;12:93-102.

25. Robbins JA, Bertakis KD, Helms LJ, et al. The influence of physician practice behaviors on patient satisfaction. Fam Med 1993;25:17-20.

26. Coyle YM, Mercer SQ, Murphy-Cullen CL, et al. Effectiveness of a graduate medical education program for improving medical event reporting attitude and behavior. Qual Saf Health Care 2005:14:383-8.

27. Vanderheyden LC, Northcott HC, Adair CE, et al. Reports of preventable medical errors from the Alberta patient safety survey 2004. Healthc $02005 ; 8$ Spec No:107-14.

28. Moore PJ, Adler NE, Robertson PA. Medical malpractice: the effect of doctor-patient relations on medical patient perceptions and malpractice intentions. West J Med 2000;173:244-50.

29. Gallagher TH, Waterman AD, Ebers AG, et al. Patients' and physicians' attitudes regarding the disclosure of medical errors. JAMA 2003;289:1001-7.

30. Espin S, Levinson W, Regehr G, et al. Error or 'act of God'? A study of patients' and operating room team members' perceptions of error definition, reporting, and disclosure. Surgery 2006;139:6-14.

31. Rosser W, Dovey S, Bordman R, et al. Medical errors in primary care. Can Fam Physician 2005;51:386-7.

32. Moskowitz EJ, Nash DB. The quality and safety of ambulatory medical care: curren and future prospects. Am J Med Qual 2007;22:274-88.

33. Lorenzo S. Hacia nuevos planteamientos de calidad. El paciente como coprotagonista. Informe SESPAS 2008. Gac Sanit 2008;22(Suppl 1):186-91.

34. Ong LML, Haes JCJM, Hoos AM, et al. Doctor-patient communication: a review of the literature. Soc Sci Med 1995; 40:903-18.

35. Lorig K, Holman HR. Long-term outcomes of an arthritis self-management study: effects of reinforcement efforts. Soc Sci Med 1989;29:221-4.

36. Wensing M, Elwyn G. Research on patients' views in the evaluation and improvement of quality of care. Oual Saf Health Care 2002:11:153-7.

37. Mathews SC, Pronovost PJ. Physician autonomy and informed decision making Finding the balance for patient safety and quality. JAMA 2008;24:2913-15.

38. Barca I, Parejo R, Gutiérrez P, et al. La información al paciente y su participación en la toma de decisiones clínicas. Aten Primaria 2004;33:361-7.

39. Datos básicos de la Salud y los Servicios Sanitarios en España. Instituto de información sanitaria, 2003. http://www.msc.es/estadEstudios/estadisticas/docs/ FOLLETO-BAJA.PDF (accessed 20 Apr 2009).

40. Newman M. The emotional impact of mistakes on family physicians. Arch Fam Med 1996:5:71-5. 